\title{
Oyster RNA-seq Data Support the Development of Malacoherpesviridae Genomics
}

\author{
Umberto Rosani * and Paola Venier * \\ Department of Biology, University of Padua, Padua, Italy
}

The family of double-stranded DNA (dsDNA) Malacoherpesviridae includes viruses able to infect marine mollusks and detrimental for worldwide aquaculture production. Due to fast-occurring mortality and a lack of permissive cell lines, the available data on the few known Malacoherpesviridae provide only partial support for the study of molecular virus features, life cycle, and evolutionary history. Following thorough data mining of bivalve and gastropod RNA-seq experiments, we used more than five million Malacoherpesviridae reads to improve the annotation of viral genomes

OPEN ACCESS

Edited by:

Akio Adachi,

Tokushima University, Japan

Reviewed by:

Joaquin Martinez Martinez,

Bigelow Laboratory for Ocean

Sciences, United States

Timothy James Green,

Macquarie University, Australia

Tristan Renault,

French Research Institute for

Exploitation of the Sea, France

*Correspondence:

Umberto Rosani

umberto.rosani@unipd.it

Paola Venier

paola.venier@unipd.it

Specialty section:

This article was submitted to

Virology,

a section of the journal

Frontiers in Microbiology

Received: 26 April 2017

Accepted: 27 July 2017

Published: 09 August 2017

Citation:

Rosani U and Venier P (2017) Oyster

RNA-seq Data Support the

Development of Malacoherpesviridae

Genomics. Front. Microbiol. 8:1515.

doi: 10.3389/fmicb.2017.01515 and to characterize viral InDels, nucleotide stretches, and SNPs. Both genome and protein domain analyses confirmed the evolutionary diversification and gene uniqueness of known Malacoherpesviridae. However, the presence of Malacoherpesviridae-like sequences integrated within genomes of phylogenetically distant invertebrates indicates broad diffusion of these viruses and indicates the need for confirmatory investigations. The manifest co-occurrence of OsHV-1 genotype variants in single RNA-seq samples of Crassostrea gigas provide further support for the Malacoherpesviridae diversification. In addition to simple sequence motifs inter-punctuating viral ORFs, recombination-inducing sequences were found to be enriched in the OsHV-1 and AbHV1-AUS genomes. Finally, the highly correlated expression of most viral ORFs in multiple oyster samples is consistent with the burst of viral proteins during the lytic phase.

Keywords: Malacoherpesviridae, RNA-seq, viromes, bivalve, OsHV-1, Herpesvirales

\section{INTRODUCTION}

The virus family of double-stranded DNA (dsDNA) Malacoherpesviridae refers to only those Herpesvirales which affect mollusks, with the Haliotid herpesvirus, and bivalve Ostreid herpesvirus1 being highly similar virus variants and the only family members described so far (Davison et al., 2005; Savin et al., 2010). Based on phylogenetic analysis, Malacoherpesviridae are distantly related to other Herpesvirales families, namely alpha-, beta-, gamma-, and allo-herpesviridae (Davison et al., 2009; Iranzo et al., 2016). In general, the considerable genome size of Herpesvirales (125-290 kb) supports complex transcriptional landscapes, including several coding (ORFs) and non-coding RNAs (ncRNAs) such as microRNAs (miRNAs). Modulation of latent vs. lytic phases guarantees long-term survival and efficient propagation of Herpesvirales, although viral genomes are exposed to mutational pressure during their latency state into the cell nucleus (Brown, 2014). In alpha- and gamma-herpesvirales, different recombination-initiating motifs can activate host genome integrity pathways like homologous recombination-dependent DNA repair (HR), a virus-protective strategy proposed as being crucial for Herpesvirales biology (Brown, 2017; Piekna-Przybylska et al., 2017). 
Speed, sensitivity, and resolution of current high-throughput sequencing (HTS) technologies have been successfully used to unlock the transcriptional landscape of Kaposi's sarcomaassociated herpesvirus, which is characterized by alternative splicing of viral introns, polycistronic mRNAs, alternative transcription starting sites, and a significant repertoire of ncRNAs (Arias et al., 2014; Strahan et al., 2016). Although transcriptome complexity could be a general feature of Herpesvirales (Stern-Ginossar et al., 2012; Oláh et al., 2015; Tombácz et al., 2016), their marked host-adaptation and phylogenetic diversity discourage any oversimplification.

As reported in Table 1, the Malacoherpesviridae genomes of Ostreid herpesvirus type-1 (OsHV-1), Chlamys acute necrobiotic virus (AVNV), and Haliotid herpesvirus 1 (AbHV-1-AUS) were sequenced in 2005, 2010, and 2013, respectively. A micro-variant genome called $\mu$ Var was described in 2010 by mapping its sequence differences on the OsHV-1 genome; a further variant of OsHV-1 (OsHV-1-SB) from diseased Scapharca broughtonii and a Taiwanese variant of AbHV-1-AUS (AbHV-1-TAI) were sequenced and recorded at NCBI in 2015 and 2016, respectively. So far, most published studies have focused on the variant $\mu$ Var, a genotype associated with severe and worldwide events of Crassostrea gigas mortality (Segarra et al., 2010; Arzul et al., 2017). The variant $\mu$ Var differs from the reference genome because of small and large deletions and due to some single nucleotide changes (Segarra et al., 2010). Viruses most likely exist as a mixture of genotypes, and also a recent analysis of OsHV1 DNA occurring in wild oyster stocks in Italy indicated the co-occurrence of slightly different OsHV-1 genotypes (Burioli et al., 2016). Expression profiles of both C. gigas and OsHV-1s have been investigated by suppression subtractive hybridization (Renault et al., 2011), qPCR (Segarra et al., 2014b; Green et al., 2015a) and by dual RNA-seq applied to oysters which were experimentally infected ( $\mathrm{He}$ et al., 2015) and naturally infected (Rosani et al., 2015). Although OsHV-1 genotypes have been mainly reported in Pacific oysters, OsHV-1 was recently associated with mortality events of the Chinese bivalve S. broughtonii (Renault et al., 2012; Bai et al., 2015; Xia et al., 2015), whereas other bivalve spp. might act as simple virus carriers (Burge et al., 2011) or be not susceptible (Tan et al., 2015). In the same way, the closely related abalone herpesvirus represents an important pathogen for the gastropod family of
Haliotis spp. (Chang et al., 2005; Savin et al., 2010; Corbeil et al., 2016). Overall, the lack of stringent host-virus specificity indicates Malacoherpesviridae as dangerous pathogens for the entire mollusk aquaculture sector.

While the analysis of infected samples has greatly advanced the general understanding of antiviral pathways in bivalve mollusks (Renault et al., 2011; Corporeau et al., 2014; Segarra et al., 2014a; Green et al., 2015b; Moreau et al., 2015; Martenot et al., 2017), the biology of Malacoherpesviridae is still obscure. The uniqueness of this viral family within the frame of poorly characterized marine mollusk viromes raises questions as to their evolutionary history, infection mechanisms in different hosts, and the functional roles of their proteins. In the absence of permissive cell lines, the development of "ad hoc" HTS approaches is today the most promising way to disclose the Malacoherpesviridae peculiarities.

In the present work, we used available mollusk RNA-seq data as a source of Malacoherpesviridae reads to perform a detailed genomic remapping. Also in comparison with the most recently sequenced virus genomes, we present and discuss the diversity and uniqueness of Malacoherpesviridae, taking into consideration SNPs and sequence motifs and raising some annotation incongruities. In particular, we report the identification of Malacoherpesviridae-like elements endogenously occurring in invertebrate genomes, and sequence motifs related to viral genome protection mechanisms and comprehensive OsHV-1 transcription data.

\section{MATERIALS AND METHODS}

\section{Sequence Data}

We retrieved the whole genome sequences and classification of 2,665 dsDNA viruses, including 82 Herpesvirales, from the NCBI database. A total of 96 RNA-seq (Zhang et al., 2012) and 8 miRNA-seq (Xu et al., 2014) samples from C. gigas as well as 159 RNA-seq samples from different Haliotis spp. were retrieved from the SRA archive (Supplementary File 1). The C. gigas genome was obtained from Ensemble Metazoa v.3 (Zhang et al., 2012). MiRBase release 21 was downloaded from http://www. mirbase.org/ (Kozomara and Griffiths-Jones, 2014). Additionally, scaffolds of genome drafts of Cephalochordates (Branchiostoma floridae, Branchiostoma belcheri, and Asymmetron lucayanum),

TABLE 1 | Malacoherpesviridae genomes.

\begin{tabular}{|c|c|c|c|c|c|c|}
\hline Virus name & & Preferred host & NCBI ID & Genome size (kb) & No. of annotated ORF & References \\
\hline \multirow[t]{4}{*}{ Bivalve- } & OsHV-1 [1] & C. gigas & AY509253 & 207 & 136 & Davison et al., 2005 \\
\hline & OsHV-1- $\mu$ VAR [2] & C. gigas & / & 201 & 134 & Segarra et al., 2010 \\
\hline & OsHV-1-SB [3] & S. broughtonii & KP412538 & 199 & 66 & Xia et al., 2015 \\
\hline & AVNV [4] & Chlamys spp. & GQ153938 & 211 & 134 & Ren et al., 2013 \\
\hline \multirow[t]{2}{*}{ Gastropod- } & AbHV-1-AUS [5] & Abalone spp. & NC_018874 & 212 & 118 & Savin et al., 2010 \\
\hline & AbHV-1-TAl [6] & Abalone spp. & KU096999 & 199 & 74 & NCBI, April 2016 \\
\hline
\end{tabular}

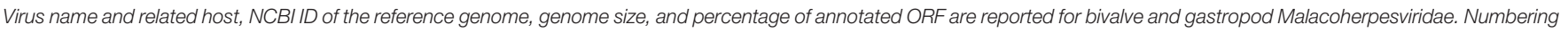
in square brackets is a reference for Table 3. 
Annelida (Capitella teleta, Hydroides elegans, and Helobdella robusta), gastropods (Lottia gigantea, Aplysia californica, and Conus tribblei), and bivalves (Mytilus galloprovincialis, $C$. virginica, Mizuhopecten yessoensis, Modiolus philippinarum, and Bathymodiolus platifrons) were retrieved from the NCBI archive and used to compose a genomic blast database (Camacho et al., 2009).

\section{Identification and Mapping of Malacoherpesviridae Reads}

If not differently indicated, all the analyses were performed using CLC Genomic Workbench v.10.0 (Qiagen, Germany). RNA reads were trimmed for quality, allowing a maximum of two ambiguous bases and a quality threshold of Q20. To reduce false positive viral hits, the mapping of $C$. gigas RNAseq reads on the oyster genome was performed with the large gap read mapping (LGRM) tool. Sequence reads not mapping on the $C$. gigas genome were stringently mapped ( 0.9 and 0.9 for length and similarity fraction, respectively) on known Malacoherpesviridae genomes and the resulting positive hits were labeled as "Malacoherpesviridae reads" and retained for subsequent analyses. Viral spliced reads were retrieved by mapping the reads on known Malacoherpesviridae genomes with LGRM. In the absence of Haliotid spp. genomes, abalone RNA reads were directly mapped on known Malacoherpesviridae genomes with stringent mapping parameters.

\section{Sequence Alignment and Phylogenetic Analysis}

Malacoherpesviridae genomes were aligned with the progressive Mauve algorithm included in the MAUVE tool (Darling et al., 2010). Malacoherpesviridae ORFs were compared with other Herpesvirales ORFs extracted from the downloaded genomes. Predicted proteins were aligned with MUSCLE v.3.8 (Edgar, 2004) and phylogenetic trees were generated using the Neighbor Joining algorithm and UPGMA algorithms, with Jukes-Cantor distance estimation and applying 1,000 bootstrap replicates with a significance cut-off set at 500. Blast searches were performed locally using BLAST+ (Camacho et al., 2009), whereas conserved domains as well as peptide and transmembrane regions were identified by using InterProScan v.60, SignalP, and THMM tools, respectively (Petersen et al., 2011). Putative Malacoherpesviridae endogenous viral elements (EVEs) were searched on 15 invertebrate genomes using tblastn with a cut-off $E$-value of $10^{-50}$ with all the OsHV-1 ORFs as query. The resulting hits were extracted and further inspected.

\section{Prediction of miRNA Precursors and Recombination-Initiating Motifs}

Two ab-initio tools for the detection of miRNA precursors were tested on Malacoherpesviridae genomes, namely miRPara (Wu et al., 2011) and VMir (Grundhoff et al., 2006). Briefly, miRPAra is a Support Vector Machine tool that provides 76 parameters predictive of putative hairpin regions on the basis of experimentally verified animal, plant, and virus miRNA models. VMir slides a sequence window of adjustable size across the viral genomes and then employs the RNA fold algorithm to predict structures with minimal free energy folding. Pre-miRNA candidates were identified and scored by evaluating the structural features of known pre-miRNA hairpins. Results obtained with miRPAra and VMir were compared and only common predicted structures were retained as putative Malacoherpesviridae miRNAs. To ascertain the presence of any viral miRNAs among C. gigas miRNA-seq reads, de-novo assembled consensus sequences generated from the 8 miRNA-seq samples were mapped on both C. gigas and Malacoherpesviridae genomes.

Nucleotidic motifs indicative of polyadenylation sites (PAS) or representative of conserved patterns were identified by simple textual searches along whole Malacoherpesviridae genomes or by applying the MEME tool (Bailey and Elkan, 1994) in the $3^{\prime}$ and $5^{\prime}$ UTR ORF regions (the latter were defined as the $100 \mathrm{nt}$ before the starting codon and after the stop codon, respectively). All viral dsDNA genomes were scanned for the presence of six recombination-initiating motifs possibly activating homologous recombination-dependent DNA repair (host HR), and enrichment ratios were calculated as reported in (Brown, 2014). Briefly, sequence motifs were identified in both original sequences and randomized sequences obtained with shuffleseq (default parameters, EMBOSS Explorer, http://cys. genomics.purdue.edu/emboss/), and then counted. The amount of a given sequence motif in each viral genome was normalized by genome length before computing the motif enrichment (ratio higher than two between original and randomized sequences).

\section{OsHV-1 Expression Analysis and SNP Calling}

To quantify the expression of viral ORFs, all Malacoherpesviridae reads were stringently mapped on the OsHV-1 reference genome (GenBank ID: AY509253) setting both length and similarity parameters to 0.9. Starting from the read counts, Transcripts Per Million (TPM) values were computed according to Wagner et al. (2013) in order to evaluate viral expression patterns by Principal Component Analysis (PCA) and ORF clustering (Euclidean distance, single linkage).

Single Nucleotide Polymorphism (SNP) analysis was performed on mapping files. Nucleotide changes were called "SNP" if present in at least $5 \%$ of the locally aligned reads using the following parameters: minimum average quality of the five surrounding bases, 15; minimum quality of central base, 20; minimum required coverage, 100x. Subsequently, SNP analysis was repeated on read mappings joined by sample origin and SNPs were compared among groups. SNP calling parameters were maintained except for the coverage, which was lowered to 20x to account for a smaller number of aligned reads.

\section{RESULTS}

\section{Tracing the Phylogenetic History of Divergent Herpesvirales (Malacoherpesviridae)}

Malacoherpesviridae display a genome size of 199-212 kb and a number of predicted ORFs ranging from 66 for AbHV-1-TAI to 
136 for OsHV-1, always covering most of the genome sequence (Table 1). As for other Herpesvirales, 5-15\% of the mollusk viral ORFs have a signal peptide region (Figure 1). Multiple alignment of whole Malacoherpesviridae genomes highlighted conserved sequence blocks clearly discriminating two genome types, namely bivalve and gastropod viruses, with very few regions of high similarity between them (e.g., ribonucleoside-diphosphate reductase, light violet blocks) and other genomic regions shared between two only of the three bivalve Malacoherpesviridae genomes (red and light green boxes, Supplementary File 2). These regions refer either to intergenic segments, like the variable microsatellite regions that differentiate OsHV-1 from the $\mu$ Var variant (Segarra et al., 2010; Martenot et al., 2013), or to deletions/insertions that modify the coding potential (e.g., the large deletion of ORF36-37 in the $\mu$ Var variant (Renault et al., 2012). Among the latter discriminant features, we remarked a 2.7 $\mathrm{kb}$ insertion characterizing the AVNV and OsHV-1-SB genomes (position 60-63 kb) and encoding three ORFs with unknown function (OsHV-1-SB ORF125, a putative secreted protein; ORF126 and ORF127, a putative transmembrane protein). We later exploited these virus-specific regions to determine which type of virus variant was present in a given RNA sample.

To obtain data useful for reconstructing the evolutionary history of Malacoherpesviridae, we searched for EVEs in a number of invertebrate genomes, including nine bivalve and gastropod genome drafts. The analyzed invertebrate genomes did not include any putative Malacoherpesviridae EVEs, the sole exception being ORFs denoting a Ribonucleotide reductase big subunit, found in the C. gigas, M. philippinarum, C. tribbei, and C. teleta genomes. As reported for B. floridae (Savin et al., 2010), we also identified a portion of a genome scaffold showing high similarity with Herpesvirales sequences in lancelet (Branchiostoma) spp. and in annelid Capitella teleta.
These scaffolds matched several Herpesvirales ORFs, including viral DNA polymerase (Table 2). Phylogenetic trees based on the catalytic subunit of DNA polymerase and generated with

TABLE 2 | Identification of Malacoherpesviridae endogenous viral elements (EVEs) in invertebrate genomes.

\begin{tabular}{|c|c|c|c|}
\hline $\begin{array}{l}\text { Malacoherpesviridae } \\
\text { ORF }\end{array}$ & Blast hit & E-value $\left(10^{\mathrm{E}}\right)$ & Scaffold ID \\
\hline \multirow[t]{3}{*}{ DNA polymerase } & C. teleta & -172 & Scaffold_559 \\
\hline & B. floridae & -104 & ABEP02031171 \\
\hline & B. belcheri & -98 & FQTN01000253 \\
\hline \multirow{3}{*}{$\begin{array}{l}\text { DNA packaging } \\
\text { terminase }\end{array}$} & C. teleta & -105 & Scaffold_559 \\
\hline & B. floridae & -99 & ABEP02031173 \\
\hline & B. belcheri & -95 & FQTN01000253 \\
\hline \multirow[t]{3}{*}{ ORF54 } & B. floridae & -98 & ABEP02031173 \\
\hline & B. belcheri & -91 & FQTN01000253 \\
\hline & C. teleta & -53 & Scaffold_559 \\
\hline \multirow{4}{*}{$\begin{array}{l}\text { Ribonucleotide reductase } \\
\text { big subunit }\end{array}$} & C.gigas & -97 & C36000 \\
\hline & C. tribbei & -65 & \\
\hline & M. philippinarum & -63 & Scaf_11254 \\
\hline & C. teleta & -61 & Scaffold_559 \\
\hline \multirow[t]{3}{*}{ ORF68-secreted protein } & B. floridae & -96 & ABEP02031173 \\
\hline & B. belcheri & -92 & FQTN01000253 \\
\hline & C. teleta & -67 & Scaffold_559 \\
\hline \multirow[t]{2}{*}{ ORF47 } & B. floridae & -74 & ABEP02031173 \\
\hline & C. teleta & -59 & Scaffold_559 \\
\hline \multirow[t]{3}{*}{ DNA primase } & C. teleta & -67 & Scaffold_559 \\
\hline & B. floridae & -62 & ABEP02031171 \\
\hline & B. belcheri & -61 & FQTN01000253 \\
\hline
\end{tabular}

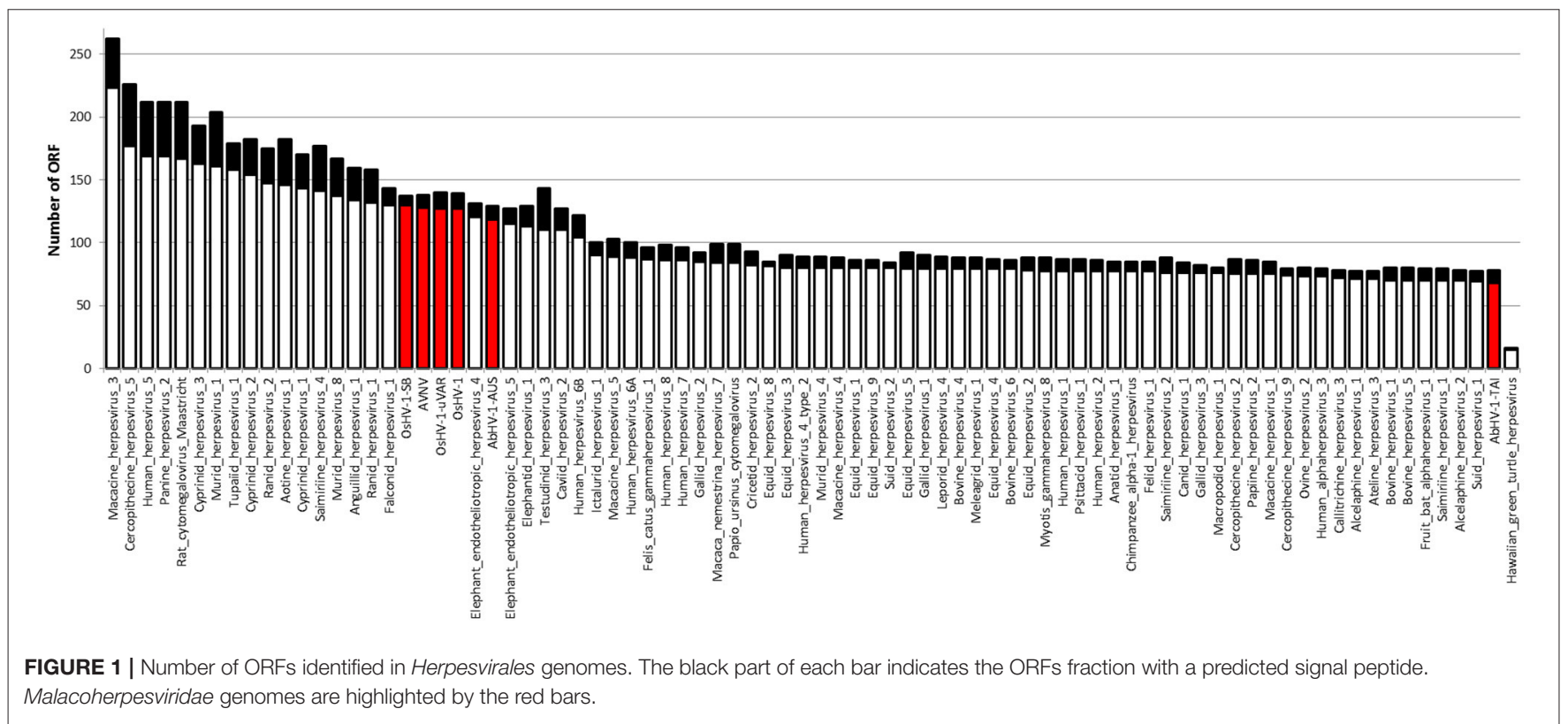


two different algorithms always showed well-supported clades for the alpha-, beta-, and gamma-Herpesviridae, and for a clade containing Malacoherpesviridae, allo-Herpesvirales, and three DNA polymerase sequences retrieved from invertebrate genomes (Figure 2). In detail, the annelid sequence clustered with bivalve Malacoherpesviridae, whereas the two lancelet sequences clustered as an out group that was more similar to abalone Malacoherpesviridae. These results further emphasize the evolutionary divergence of known mollusk viruses from other Herpesvirales as reported by Davison et al. (2005) and Iranzo et al. (2016). Moreover, the presence of Herpesvirales EVEs very similar to Malacoherpesviridae (Malacoherpesviridaelike) is confirmed not only in B. floridae (Savin et al., 2010) but also in the B. belcheri and C. teleta genomes. Depending on the applied algorithm, allo-Herpesvirales clustered as an outgroup of Malacoherpesviridae or of other Herpesvirales (data not shown).

\section{Malacoherpesviridae-Specific Genes Support the Divergence from Other Herpesvirales}

The uniqueness of most of the Malacoherpesviridae genes hampers a comparative identification of conserved protein domains and homologous genes in public sequence databases. Moreover, Malacoherpesviridae share amongst themselves, and with other Herpesvirales, a small number of protein domains which mainly pertain to transcription-related proteins. As previously reported by Davison et al. (2005) for OsHV-1, the BIR domain (PF00653) was the only one exclusively found in all Malacoherpesviridae, whereas some other protein domains were identified as specific to bivalve or gastropod herpesviruses (Supplementary File 3). Although some Herpesvirales possess proteins inhibiting the host apoptotic pathways, e.g., proteins with a partial BIR domain or a Bcl-2-like protein (Wang et al., 2002; Gallo et al., 2017), a highly-confident BIR domain was uniquely found in Malacoherpesviridae, whereas the FIC, Exo5, and zf-RING_5 domains were detected only in bivalve Malacoherpesviridae. FIC (PF02661) characterizes proteins mediating post-translational modifications (Roy and Cherfils, 2015) and Exo5 characterizes the same clan of other herpesvirus exonucleases (Herpes_UL24 and Herpes_alk_exo domains) including the gastropod Malacoherpesviridae exonuclease (PDDEXK_1 domain). Through stable coordination of $\mathrm{Zn}$ cations, zf-RING_5 fingers acquire different binding specificities for DNA, RNA, proteins, and/or lipid targets, and therefore pleiotropic roles. For instance, the RING domain of the immediate-early protein (ICPO) of herpes simplex virus 1 (HSV-1) has ubiquitin ligase activity, enabling protein targeting for degradation, and inhibits interferon-stimulated host gene production (Taylor et al., 2014). As reported in Figure 3 and Table 3, the higher number of protein domains unique to gastropods and related to bivalve Malacoherpesviridae (12 and 3 , respectively) is mainly due to a couple of viral genes including six protein domains and encoding a DNA ligase (present on both AbHV-1-AUS and AbHV-1-TAI genomes) and a methyltransferase-like (present uniquely in AbHV-1-AUS).

\section{Putative Protein Counterparts of Malacoherpesviridae-Specific Domains}

We further investigated the putative origin of viral genes including Malacoherpesviridae-exclusive (among Herpesvirales) protein domains by domain-based searches of similar genes in public databases (NCBI) and in available mollusk genomes. Accordingly, we were able to assign Malacoherpesviridae-specific domains to 17 viral genes, present in all or some of the known Malacoherpesviridae. Eleven of them matched mollusk counterparts with similar domain organization (blastp similarity value $<10^{-5}$ ). Searches within the $C$. gigas gene models identified genes characterized by BIR, guanylate kinase, DNA ligase, FIC, and eukaryotic translation initiation factor domains. Other Malacoherpesviridae-specific domains showed scarce similarity with host genes characterized by EXO5, PDDEXK_1, zf-RING_5 and Sprt-like domains, whereas the viral RNA-lig_T4_1 and methyltransferase domain did not find any similarity (Table 3).

BIR was detected in four bivalve herpesvirus genes and in two AbHV-1-AUS genes (absent in AbHV-1-TAI). Moreover, BIR was highly represented in the $C$. gigas genome, with the oyster protein EKC36433 (initial part of it) showing surprising similarity to one viral gene. Among the viral FICs, only those from dsDNA viruses (not from phages) showed strong conservation of the nineresidue signature of the FIC motif (HPFX(D/E)GNGR) (Roy and Cherfils, 2015), whereas the other hits displayed less-conserved motifs, as observed for some bacterial proteins (Khater and Mohanty, 2015). Some other domains of Malacoherpesviridaespecific genes are also present in other dsDNA viruses or in bacteria. The Exo5 exonuclease of bivalve Malacoherpesviridae is unique among viruses, whereas the PDDEXK_1 exonuclease of gastropod Malacoherpesviridae shows a wide distribution in the Caudovirales family and in other DNA viruses. Finally, the methyltransferase-like protein unique to AbHV-1-AUS showed similarity with bacterial and (a few) viral proteins (mainly from phages).

\section{Only C. gigas RNA-seq Samples Include Genuine Malacoherpesviridae Reads}

We considered a total of 96 C. gigas and 159 Haliotis spp. RNA-seq samples, accounting for more than 5.5 billion reads, to identify reads generated by transcriptionally active Malacoherpesviridae. Before mapping the mollusk RNA sequences on Malacoviridae genomes, we exploited the C. gigas genome to filter out all host reads from the C. gigas RNA-seq samples. Since a Haliotid genome draft was not available, we directly mapped abalone RNA-seq reads on Malacoherpesviridae genomes. Stringent mapping of oyster-genome-unmapped reads on known Malacoherpesviridae genomes allowed for the selection of $5.483 \mathrm{M}$ reads from the 2.27 billion starting dataset $(0.24 \%)$, whereas stringent mapping of the Haliotis spp. reads produced only $0.01 \%$ of mapped reads, with very few reads correctly paired. Manual examination of the mapping files revealed the matching of the gastropod reads to viral oligo-nucleotidic stretches, a fact greatly impairing the mapping specificity. Conversely, the viral reads retrieved from $C$. gigas samples showed a pairing correctness of $94.2 \%$, thus 


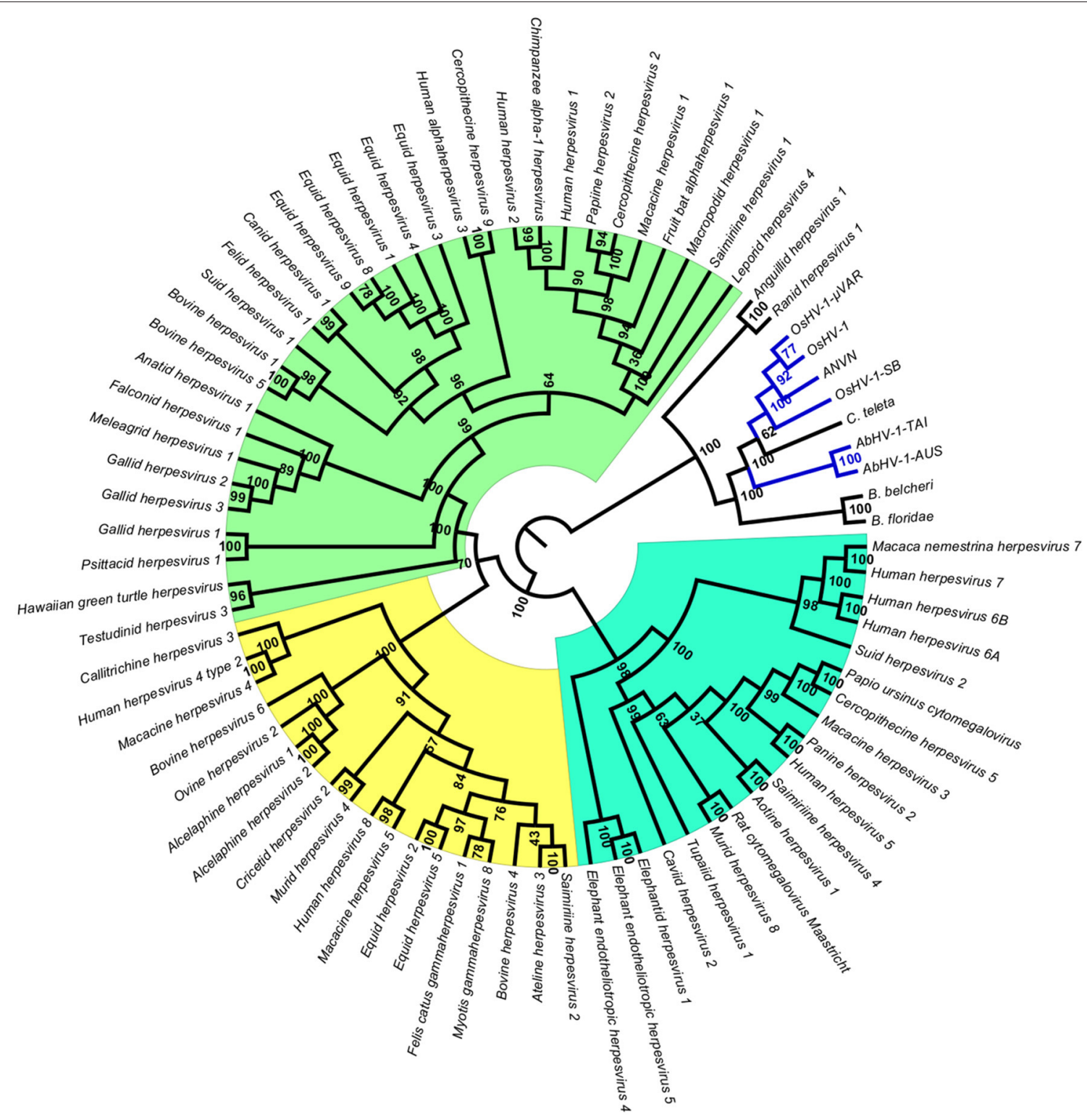

FIGURE 2 | Phylogenetic tree of catalytic subunit of DNA polymerase. The blue lines represent Malacoherpesviridae hits. Background colors highlight alpha-Herpesvirales in green, beta-Herpesvirales in blue, and gamma-Herpesvirales in yellow. The circular cladogram was computed with the Neighbor Joining algorithm and Jukes-Cantor distance estimation. Bootstrap values are reported for each node as percentages calculated over 1,000 performed replicates, with a significance cutoff set at 500 .

demonstrating that only the C. gigas RNA-seq samples contained genuine Malacoherpesviridae reads. All analyzed oyster RNA samples (ten of them comprising $90 \%$ of the total reads) included at least a few bivalve Malacoherpesviridae transcripts (Supplementary File 1). The RNA-seq sample richest in viral reads ( $3.5 \%$ of the total reads) was from a naturally-occurring infection previously described (Rosani et al., 2015). Viral transcripts were also abundant in samples from more susceptible life stages (larvae, spat, juveniles) and at $24 \mathrm{~h}$ post-infection with the variant $\mu$ Var (only two of the ten richest RNA-seq samples derived from infection trials) (He et al., 2015).

\section{Malacoherpesviridae Reads Are produced by Slightly Different Viral Variants}

We further considered the Malacoherpesviridae reads mapping on the virus-specific regions previously identified by whole genome alignment (Supplementary File 2). Stringent backmapping of these reads on sequential combinations of bivalve Malacoherpesviridae genomes $(0.9$ of sequence similarity computed along the whole read length) supported the assignment of $4.903 \mathrm{M}$ (out of $5.483 \mathrm{M}$ reads) to Malacoherpesviridae genomes, with residual $\sim 580 \mathrm{k}$ reads failing the genome assignment step (Table 4). Many of the latter (348 k reads) could 


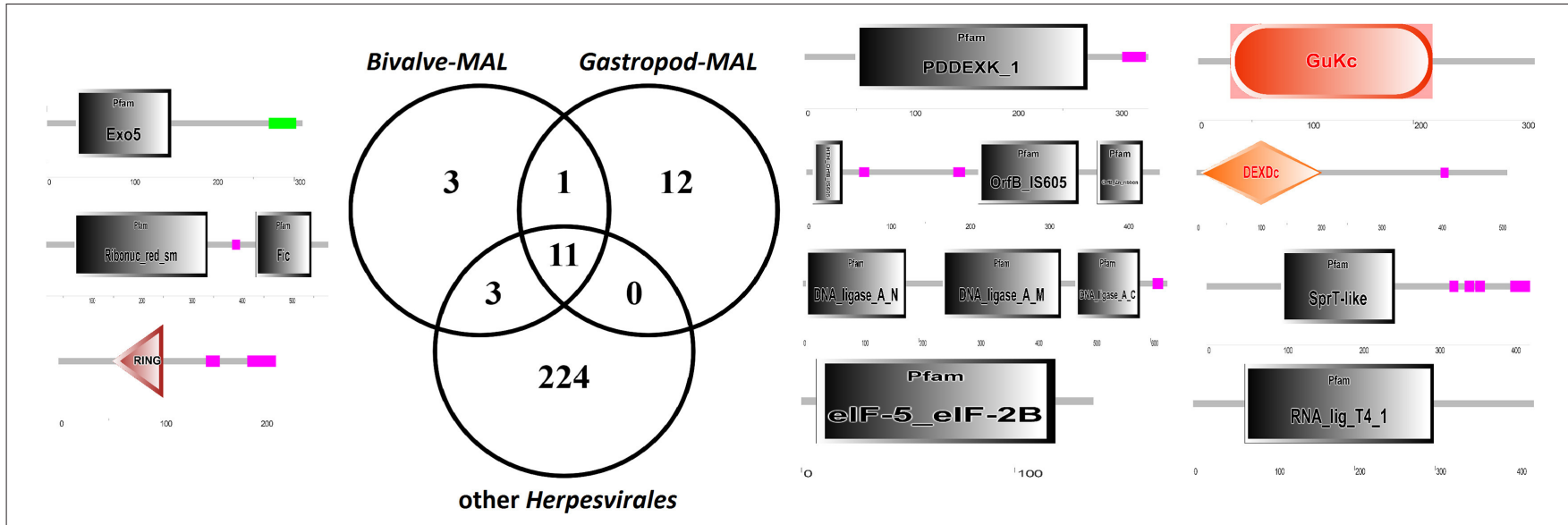

FIGURE 3 | Venn diagram of the protein domains detected in bivalve Malacoherpesviridae, gastropod Malacoherpesviridae, or other Herpesvirales. Organization of protein domains (with PFAM IDs) of bivalve-exclusive (left) and gastropod-exclusive (right) viral proteins.

TABLE 3 | Viral ORFs with Malacoherpesviridae-specific protein domains.

\begin{tabular}{|c|c|c|c|c|c|}
\hline \multirow[t]{2}{*}{ ORF annotation } & \multirow[t]{2}{*}{ Virus ID } & \multirow[t]{2}{*}{ Domain ID } & \multirow[t]{2}{*}{ No. of MAL gene } & \multicolumn{2}{|l|}{ Domain occurrence } \\
\hline & & & & Other viruses & $\begin{array}{l}\text { Mollusk } \\
\text { genomes }\end{array}$ \\
\hline Apoptosis inhibitor & $1,2,3,4,5,6$ & $\mathrm{BIR}$ & $18(6)$ & dsDNA and RNA viruses & Yes \\
\hline $\begin{array}{l}\text { Ribonucleotide reductase, } \\
\text { s.s. }\end{array}$ & $1,2,3,4$ & Ribonuc_red_sm, Fic & $4(1)$ & Caudovirales, Nimaviridae, Nudiviridae & Yes \\
\hline Guanylate kinase & 5,6 & Guanylate_kin & $2(1)$ & Poxviridae, Caudovirales & Yes \\
\hline DNA ligase & 5,6 & $\begin{array}{l}\text { DNA_ligase_A_M, } \\
\text { DNA_ligase_A_N, DNA_ligase_A_C }\end{array}$ & $2(1)$ & dsDNA viruses & Yes \\
\hline $\begin{array}{l}\text { Eukaryotic translation } \\
\text { initiation factor- } 5\end{array}$ & 5 & elF-5_elF-2B & $1(1)$ & Baculoviridae, Marseilleviridae & Yes \\
\hline Exonuclease & $1,2,3,4$ & EXO5 & $4(1)$ & / & Low similarity \\
\hline Exonuclease & 5,6 & PDDEXK_1 & $2(1)$ & dsDNA viruses, Caudovirales & Low similarity \\
\hline / & 5,6 & SprT-like & $2(1)$ & Caudovirales, Baculoviridae & Low similarity \\
\hline RNA helicase & 5,6 & Reslll & $2(1)$ & dsDNS and ssRNA viruses & Low similarity \\
\hline Zinc finger & $1,2,3,4$ & zf-RING_5 & $4(1)$ & Mimiviridae & Low similarity \\
\hline RNA ligase & $5,6^{\star}$ & RNA_lig_T4_1 & $2(1)$ & Caudovirales, Baculoviridae & No \\
\hline $\begin{array}{l}\text { Methyltransferase/ } \\
\text { transposase }\end{array}$ & 5 & $\begin{array}{l}\text { OrfB_Zn_ribbon, } \\
\text { OrfB_IS605, } \\
\text { HTH_OrfB_IS605 }\end{array}$ & $1(1)$ & Caudovirales Mimiviridae Phycodnaviridae & No \\
\hline
\end{tabular}

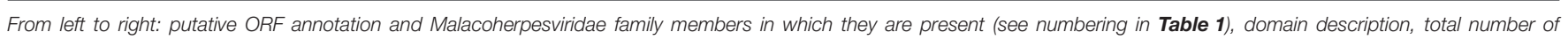

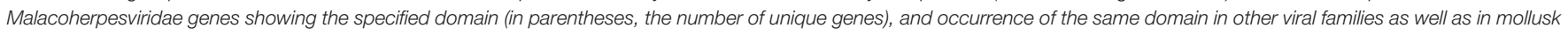
genomes.

*Partial or incomplete sequences are also present in bivalve Malacoherpesviridae.

be mapped anyway by gradually lowering the similarity mapping parameter to 0.5 , a fact suggesting a certain degree of variability of viral RNA reads. Sequential genome mapping showed that 20,251 reads not matching an OsHV-1 sequence region could be re-assigned to a genomic region of AVNV, or OsHV-1-SB (60-63 $\mathrm{kb}$ ) including a $2.7 \mathrm{~kb}$ insertion typical of these two genomes. De-novo assembling of these 20,251 reads confirmed the presence of ORF125 and ORF126, out of the three AVNV ORFs annotated in this region (ORF125-ORF127). A total of 4,461 other reads were attributed to a deletion on ORF103, typical of both OsHV-1 and OsHV-1-SB but absent in AVNV, suggesting the occurrence of a mixture of viral genotypes in the analyzed RNA-seq samples (Table 5). To further endorse this hypothesis, we searched for viral spliced reads. Spliced reads normally result from the mapping of one mRNA read over an intron sequence, whereas in our analysis they were attributed to insertions or deletions occurring in the viral reference genome. Using ultra confident mapping parameters, like 0.95 and 0.95 for similarity and length fraction, we were able to re-assign a portion of the 11,947 spliced reads to the $\mu$ Var variant and AVNV genomes (Table 6). All the 
AVNV-re-assigned reads mapped on a 9-nt deletion of ORF104, the one discriminating AVNV from other Malacoherpesviridae.

\section{Read Mapping Highlights Few Annotation Inconsistencies in the OsHV-1 Genome}

Coverage graph analysis is a powerful tool for detect sequencing anomalies. If reads are unbiasedly produced, the coverage should appear quite homogenous along the entire sequence, even if a $5^{\prime}$ peak may be due to the random fragmentation of multiple mRNA copies of any given transcript, as reported by Arias et al. (2014). Manual inspection of the coverage graph (Figure 4A) along the OsHV-1 genome highlighted a few anomalies. In the ORF104 graph (Figure 4B), two distinct peaks are indicative of a mismatch region impairing the read mapping and confirmative of above reported results. In the ORF107 graph (Figure 4C), highly uneven coverage (from 250x, along the first 1,000 nucleotides, to $4,800 \mathrm{x}$ ) suggested the presence of two nested ORFs with completely different expression levels. In fact, we recognized two small ORFs, both of 152 AA length and one of them including three transmembrane regions (Figure 4).

Moreover, the coverage graph showed that some reads mapped on the five large intergenic OsHV-1 regions. As previously reported, these regions contain non-coding, disrupted ORFs (Davison et al., 2005; He et al., 2015). Following de-novo assembling of the reads corresponding to said genomic regions, we recovered few complete ORFs. Although the assembled reads were retrieved from different RNA samples, nearly all of them clustered in one consensus sequence (Table 7). In detail, the consensus sequences generated for the $50 \mathrm{k}$ and $99 \mathrm{k}$ regions were similar to ORF88 (transmembrane OsHV-1 protein), whereas the consensus sequence for the $113 \mathrm{k}$ region showed similarity to a

TABLE 4 | Identification of Malacoherpesviridae reads in C. gigas RNA-seq data.

\begin{tabular}{lc}
\hline Analysis step & No. of reads \\
\hline Total analyzed reads & $2.27 \mathrm{G}$ \\
Putative Malacoherpesviridae reads & $5,483,402$ \\
Malacoherpesviridae assigned reads & $4,903,646$ \\
Un-assigned reads & 579,576 \\
Spliced reads & 11,947
\end{tabular}

The spliced reads that were recovered with a large gap mapping tool were then re-assigned to Malacoherpesviridae genomes (see Table 6). protein characterized by a domain found only in the crustacean White spot syndrome virus (Nimaviridae). Finally, for the three consensus sequences generated from the $72 \mathrm{k}$ and $94 \mathrm{k}$ regions, no similarities to any already annotated sequences were found.

\section{Malacoherpesviridae Genomes Include Few Recognizable Sequence Motifs}

We searched known Malacoherpesviridae genomes for nucleotidic motifs, oligo-nucleotidic stretches, and PAS. Simple motif searches revealed oligo-nucleotidic stretches (at least eight equal bases, mainly $\mathrm{A}$ or $\mathrm{T}$ ) were preferentially located in intergenic regions (only 20/399 were found in ORFs). Mapping canonical PAS such as AAUAAA and AUUAAA (Arias et al., 2014), we retrieved completely conserved matches in 393 of $5593^{\prime}$ UTRs. Applying a more sophisticated tool (MEME) to the $5^{\prime}$ and $3^{\prime}$ UTR regions, we identified a longer PAS motif in $1263^{\prime}$ UTRs and a second $3^{\prime}$ UTR motif. Unfortunately, the diffuse presence of $\mathrm{T}$-stretches in intergenic regions hampered the mapping of reads containing $3^{\prime}$ polyadenylated bases and, hence, an elegant identification of transcript ends, as described by Stern-Ginossar et al. (2012). None of the MEME-proposed $5^{\prime}$-motifs were statistically convincing enough.

\section{Two DNA Recombination-Initiating Promoter Motifs Are Enriched among Malacoherpesviridae}

We initially investigated the presence of six HR promoter motifs in two reference Malacoherpesviridae genomes (OsHV-1 and AbHV-1-AUS for bivalve and gastropod viruses, respectively)

TABLE 6 | Re-assignment of spliced reads to Malacoherpesviridae genomes.

\begin{tabular}{lccccc}
\hline $\begin{array}{l}\text { Spliced reads } \\
\text { identified in }\end{array}$ & $\begin{array}{l}\text { No. of } \\
\text { reads }\end{array}$ & \multicolumn{5}{c}{ Re-assigned to } \\
\cline { 3 - 6 } & & OsHV-1 & $\begin{array}{c}\text { OsHV-1 } \\
\text { OVAR (\%) }\end{array}$ & OsHV-1-SB & AVNV (\%) \\
\hline OsHV-1 & 4,640 & $/$ & 6 & - & 92 \\
OsHV-1 $\mu$ VAR & 4,583 & - & $/$ & - & 93 \\
OsHV-1-SB & 1,959 & - & 19 & $/$ & 51 \\
AVNV & 542 & - & 47 & - & $/$ \\
\hline
\end{tabular}

Origin and number of spliced reads and the re-assignment percentages are reported.

TABLE 5 | Detailed analysis of three RNA-seq samples rich in viral reads.

\begin{tabular}{|c|c|c|c|c|c|c|c|c|}
\hline \multirow[t]{2}{*}{ Sample ID } & \multirow[t]{2}{*}{ Total reads } & \multirow{2}{*}{$\begin{array}{l}\text { C. gigas unmapped } \\
\text { reads [\%] }\end{array}$} & \multicolumn{6}{|c|}{ Malacoherpesviridae reads } \\
\hline & & & Total reads & $\begin{array}{c}\text { Reads on } \\
\text { unique regions }\end{array}$ & OsHV-1 & OsHV-1- $\mu$ var & AVNV & OsHV-1-SB \\
\hline E-MTAB-2552 & $85,335,256$ & 32 & $3,003,873$ & 274,187 & $3.1 \%$ & $95.0 \%$ & $0.5 \%$ & $1.5 \%$ \\
\hline SRR334249 & $26,566,768$ & 39 & $1,175,934$ & 26,401 & $7.8 \%$ & $55.0 \%$ & $17.0 \%$ & $20.0 \%$ \\
\hline SRR2002949 & $6,538,514$ & 36 & 73,212 & 5,951 & $0.9 \%$ & $93.2 \%$ & $2.3 \%$ & $2.4 \%$ \\
\hline
\end{tabular}

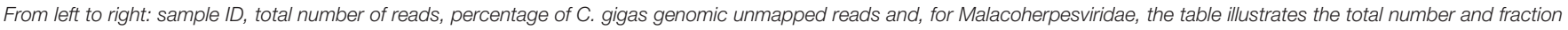
of reads mapped on unique regions of four viral genomes, with the assignment of percentages to each individual virus. 


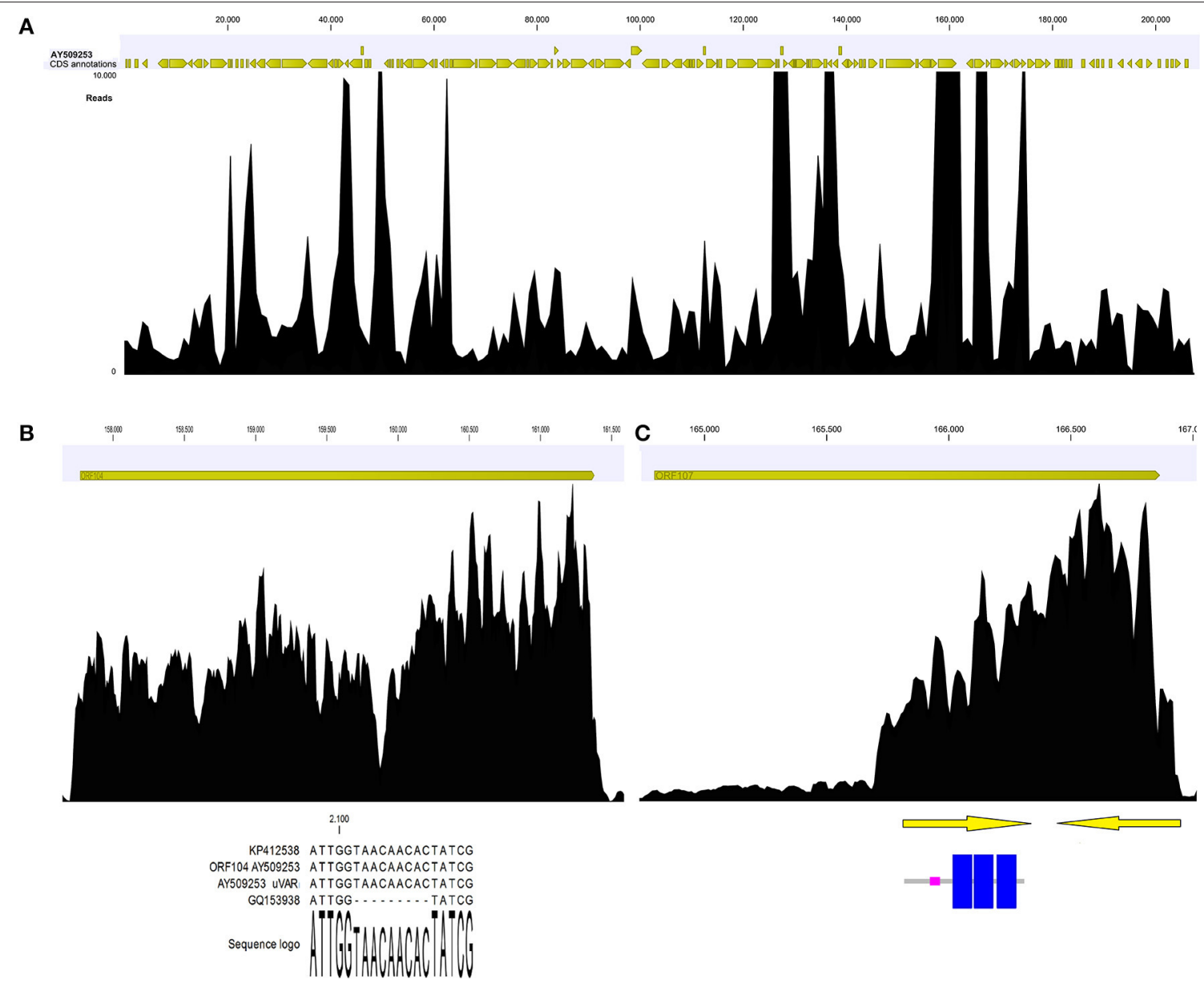

FIGURE 4 | Coverage graph of Malacoherpesviridae reads (A). Coverage graph of the whole OsHV-1 genome, as obtained by mapping 4.9 M viral reads with length and similarity mapping parameters set to 0.9. Yellow arrowheads indicate annotated ORFs along the virus genome. Maximum coverage was set to 10,000x. (B) Details of the ORF104 coverage graph, with the alignment including the 9-nt deletion causing coverage drop-off. (C) Details of ORF107 coverage graph, with two nested ORFs (arrows) that could explain the local coverage bias. One ORF encoded three transmembrane regions (highlighted in blue).

TABLE 7 | De-novo assembly results of reads mapping on OsHV-1 putative coding regions.

\begin{tabular}{|c|c|c|c|c|c|}
\hline Genomic region & No. of reads & No. of samples & Assembled contigs & Genomic region & Identity (blastp) \\
\hline PUTA_50k & 112,855 & 76 & $1(66 \%)$ & $47,859-49,814$ & ORF88 [OsHV-1] \\
\hline PUTA_72k & 25,653 & 81 & 1 (93\%) & 73,359-75,186 & / \\
\hline \multirow[t]{2}{*}{ PUTA_94k } & 17,115 & 63 & $2(100 \%)$ & $93,041-94,996$ & / \\
\hline & & & & $95,053-96,949$ & / \\
\hline PUTA_99k & 55,877 & 49 & $1(100 \%)$ & $98,220-100,352$ & ORF88 [OsHV-1] \\
\hline PUTA_113k & 47,072 & 45 & $1(100 \%)$ & $112,807-114,696$ & DUF1335-domain containing protein $[113,991-114,661]$ \\
\hline
\end{tabular}

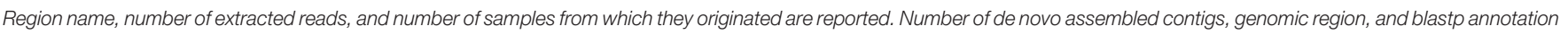
are also reported.

and then we analyzed the resulting data against 2,665 dsDNA viral genomes. Overall, we recognized 1,443,794, and 1,523,194 motifs in original and randomized viral sequences, respectively. As expected, shorter motifs were more present, whereas a classical meiotic recombination motif (CCTCCCCT) (Myers et al., 2005) was found on 1,258 genomes and was labeled as "enriched" only in 88 of them. Complete data are reported in Supplementary File 4. Among the 104 invertebrate dsDNA viruses present in the dataset, only a truncated chi-motif (TGGTGG) (Chuzhanova et al., 2009) was widely enriched (in around $50 \%$ of the viruses, including OsHV-1 but not AbHV-1-AUS). The CCTCCCCT motif was computed as being 
TABLE 8 | miRNA prediction results. miRPara and vMir predictions are reported for the six Malacoherpesviridae genomes, with total number of predicted regions, common ones and percentage of those located in ORFs.

\begin{tabular}{lcccc}
\hline Species & miRPara & vMir & common & \% on ORF \\
\hline Total & 866 & 247 & 96 & 53 \\
OsHV-1 & 98 & 37 & 11 & 45 \\
OsHV-1- & 107 & 37 & 12 & 58 \\
OsHV-1-SB & 87 & 43 & 14 & 50 \\
AVNV & 94 & 39 & 14 & 43 \\
AbHV-1-AUS & 242 & 33 & 25 & 52 \\
AbHV-1-TAl & 238 & 58 & 20 & 65 \\
\hline
\end{tabular}

"enriched" only in four invertebrate viruses, namely the two Malacoherpesviridae, White spot syndrome virus, and Invertebrate iridescent virus 6, a virus for which the interaction with mammalian antiviral systems was recently reported (Ahlers et al., 2016). The distribution of CCTCCCCT motif in known Malacoherpesviridae genomes revealed its biased presence, with most them located in the second part genomes.

\section{Do Malacoherpesviridae Genomes Encode Genuine miRNAs?}

To infer the presence of miRNAs in Malacoherpesviridae genomes, we exploited two ab-initio miRNA predictor tools. Compared with VMir, the miRPara algorithm predicted a higher number of putative structured RNAs, with a range of 11-25 predicted miRNAs per genome commonly identified (Table 8). Although most of the Malacoherpesviridae genomes are covered by ORFs, only $43-65 \%$ of the predicted miRNA structures were located in coding regions, thus indicating their preferential intergenic occurrence. None of the predicted structures found similarity in the miRBase database and, likewise, none of the miRBase hits found a decent match on Malacoherpesviridae genomes. Taking into account eight miRNA-seq samples (some of them rich in viral reads, all them belonging to the same oyster batches used to produce developmental RNA-seq libraries), we could not validate any of the predicted viral miRNA regions, nor the miRNA reads mapped to any other viral genome. These analyses do not indicate any genuine Malacoherpesviridae miRNA; more focused experiments are needed to definitively clarify this point.

\section{OsHV-1 Transcription Levels are Highly Comparable among Different RNA Samples}

We performed a detailed expression analysis by mapping the identified Malacoherpesviridae reads only on the OsHV-1 reference genome and computing the related expression values in TPM. In addition to the already annotated ORFs, we considered the genomic regions for which we had previously observed a read coverage to be "putative coding regions." The number of mapped reads as well as non-normalized (nn-TPM) and normalized (TPM) values calculated per ORF are reported in an interactive table offered as an easy tool for interested readers (Supplementary File 5). Although all 96 C. gigas RNA-seq samples included viral reads, we classified 14 of them as "high" (i.e., more than 1,000 counted viral reads, Supplementary File 1). As stated above, this classification does not directly correlate to the number of identified Malacoherpesviridae reads, since it relies only on the reads that stringently mapped on the OsHV1 reference genome (and were subsequently counted). The RNA samples in which different viral types contributed to the final amount of Malacoherpesviridae reads were remarkable (e.g., SRR334249, Table 5). Digital expression analysis highlighted few expression peaks, namely TPMs $>2 \mathrm{M}$ for ORF76, ORF80, ORF29, ORF42, ORF88, and for a putative coding region (PUTA_72k). Principal component analysis (PCA) based on TPM-values clearly supported the "high-expression" grouping based on the counted reads (Supplementary File 6.1). Few ORFs were expressed in almost all RNA-seq samples, such as ORF76, which represents $13 \%$ of the total TPMs and has an extremely high relative expression in every sample (although significantly expressed also in "high" samples, as showed by nonTPMs). On the contrary, several ORFs showed a preferential occurrence in selected samples, like ORF27, ORF45, ORF80, ORF82, ORF90, ORF104, ORF107, and ORF113, which grouped in a unique expression cluster (Supplementary File 6.2). Among the several ORFs with unknown function, ORF18 encoding for a 94-aa peptide was highly expressed in multiple RNAseq samples. As clearly shown in Figure 5, almost all viral ORFs are simultaneously expressed in "high" samples, with very few line interruptions corresponding to ORF36, ORF37, and ORF48 previously reported as not functional (He et al., 2015). In agreement with the results obtained from coverage graph analysis, detectable expression levels were evident for ORF50 (PUTA_72k), ORF62 and ORF63 (PUTA_94k), ORF65 (PUTA_99k), ORF73 (PUTA_113k), and (PUTA_110k).

\section{SNPs Analysis Supports the Presence of OsHV-1 Variants within RNA Samples}

Using a conservative SNP-calling algorithm, we identified 664 variable positions consisting in changes of single nucleotides or small stretches (maximal $5 \mathrm{nt}$ ). Eighty-six percent of these SNPs mapped on annotated genes, with the majority of them (75\%) involving amino acid substitutions (nsSNP). The total SNPs were distributed on 94 ORFs (40 ORFs are invariant) and non-synonymous (ns) SNP occurred in 87 ORFs (37 ORFs display only nsSNPs, seven only synonymous ones). ORF124 and ORF18 showed the maximal frequency of SNP (1.2\%) and of nsSNP (1.1\%), respectively (Figure 6A). As reported above, the interactive Supplementary File 5 also includes the SNP frequencies for each OsHV-1 ORF. In spite of their high expression levels, some ORFs showed very few SNPs or appeared invariable, as expected in the case of strict functional constraints. Further analysis of the viral SNPs in the RNA-seq samples grouped by geographical origin produced a core set of 78 common SNPs, with the main part of them supporting an effective difference between sample groups (Figure 6B). Although most of the common SNPs concerned differences between the sampled viruses and the reference OsHV-1 (present at $100 \%$ frequency in all groups), 20 SNPs displayed a frequency 


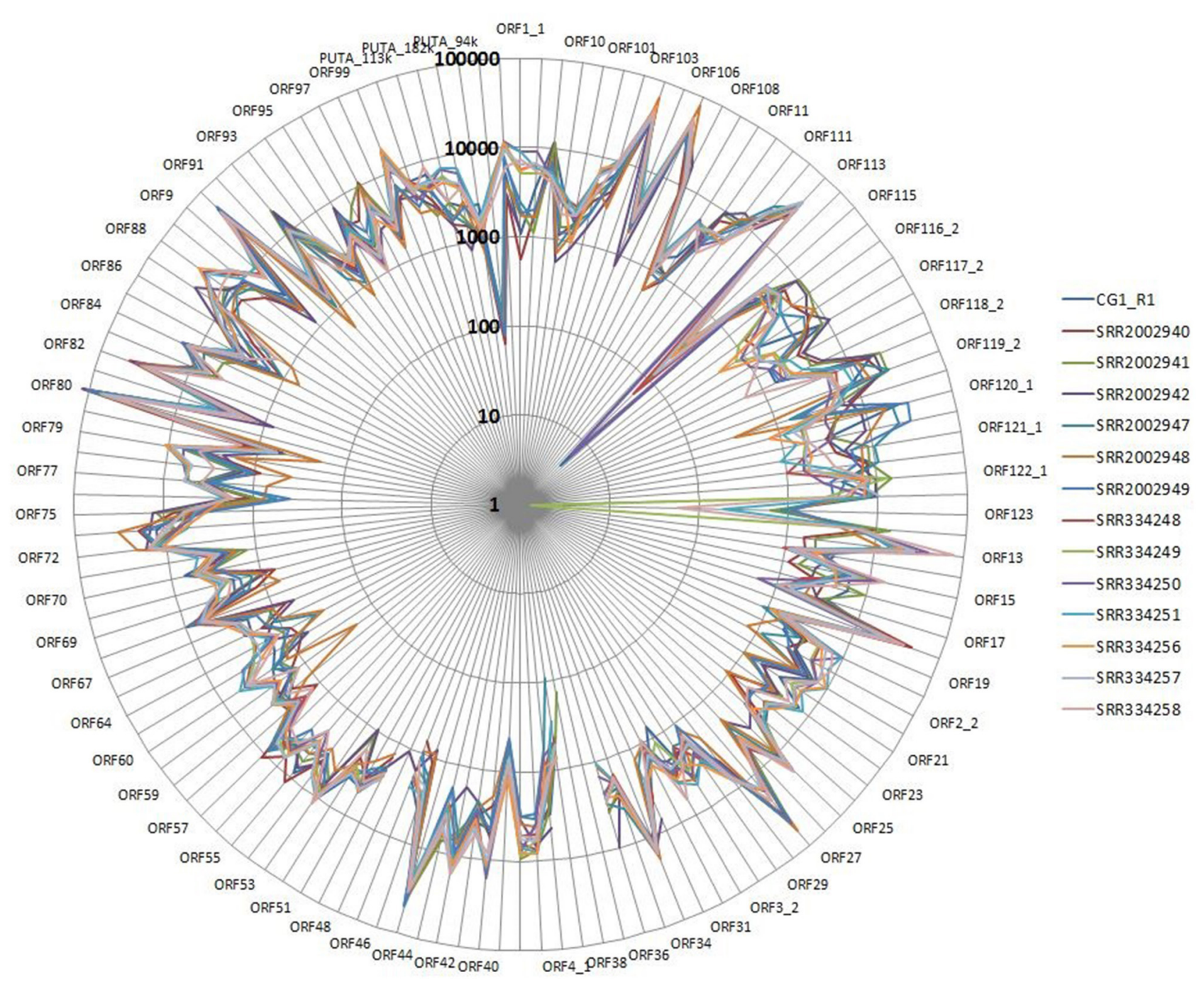

FIGURE 5 | Radar graph depicting the viral TPM values in 14 RNA-seq samples selected as "high". Expression values are reported with a logarithmic scale.

lower than $95 \%$ in at least one group. Using the frequencies of those SNPs to "genotype" undefined OsHV-1-mixtures in eight selected RNA-seq samples, we were able to infer the variable presence of slightly different viruses in single stocks of virus-infected C. gigas (Figure 6C), as previously suggested by read mapping on unique genomic regions (reported in Table 5).

\section{DISCUSSION}

HTS methodologies have extraordinarily contributed to the understanding of the viral world in the ocean (Brum et al., 2015). Even though viruses are massively present in coastal waters (Suttle, 2007), only a minimal number of them are represented in sequence databases. This bias allows for the discovery of new viruses in almost every virome study, as recently reported for six new bivalve-associated RNA viruses (Rosani and Gerdol, 2016) and for RNA viruses associated with invertebrates (Shi et al., 2016). Nevertheless, bivalve viromes essentially remain unknown, except for a few pathogenic viruses (Arzul et al., 2017).

In the present work, we focused on the family of Malacoherpesviridae, a case study considering their enigmatic evolutionary origin and limited transcriptional/genomic data. Moreover, Malacoherpesviridae represent an urgent problem for mollusk aquaculture worldwide: their recurrent association with host mortality outbreaks may lead to a better understanding of their life cycles and dynamic host-pathogen interactions, ultimately for the development of effective prevention and mitigation strategies (Davison et al., 2005; Corbeil et al., 2016; Pernet et al., 2016). The previously reported divergence of Malacoherpesviridae from other Herpesvirales suggests that long-lasting evolutionary processes may have given rise to the only Herpesvirales genomes known to infect invertebrates. Although TEM imaging of herpes-like particles supports the occurrence of Herpesvirales in corals, recent sequencing data are somewhat elusive (Correa et al., 2016). Moreover, 


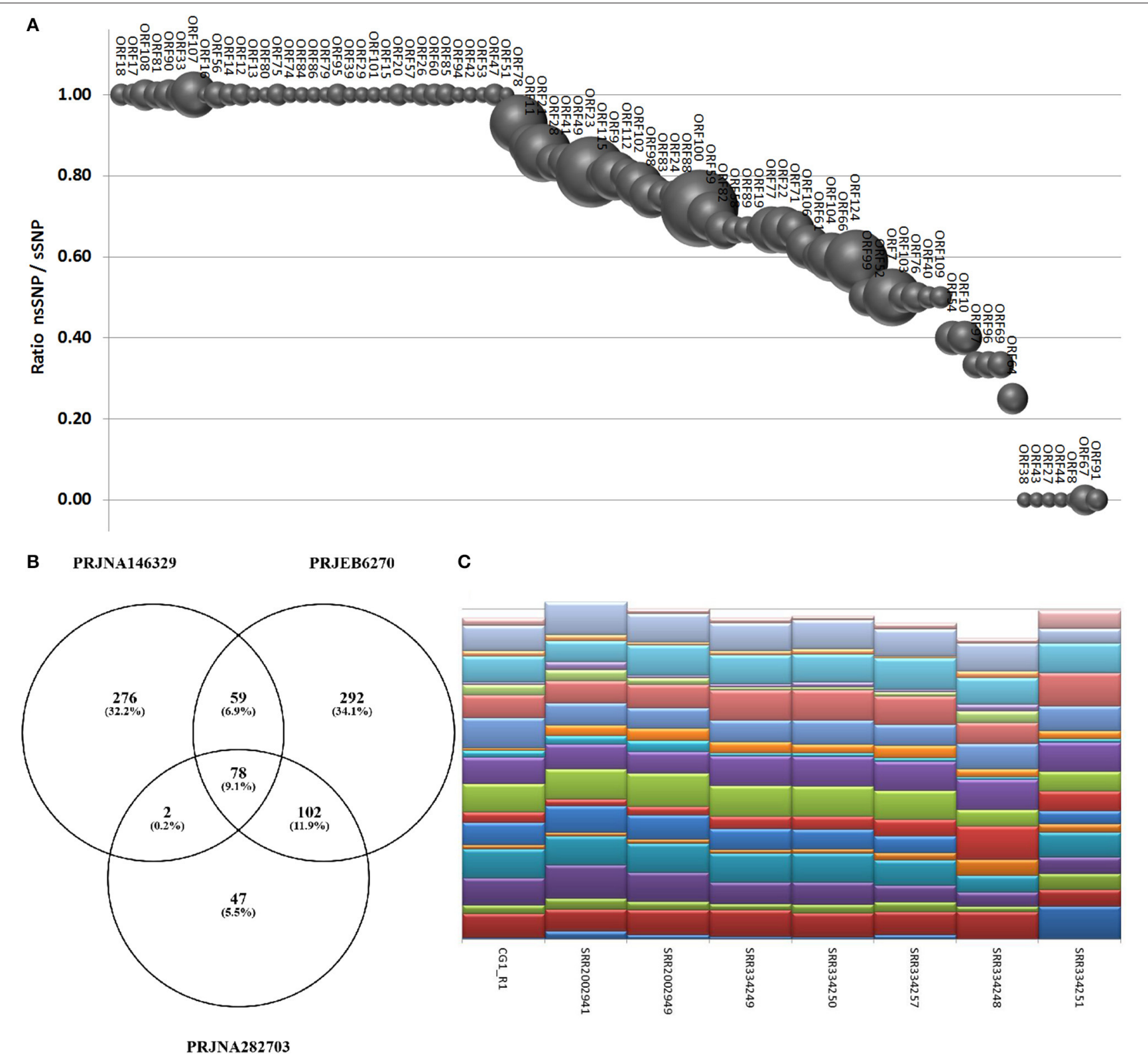

FIGURE 6 | (A) SNPs occurrence in OsHV-1 ORFs. The graph depicts the ratio of nsSNP vs. total SNP for the ORFs presenting at least one variation. Globe size is proportional to the number of SNP for each ORF. (B) Common and exclusive SNPs indicated in the Venn diagram resulted from the comparison of oyster RNA-seq samples grouped by origin. (C) "Genotyping" graph based on 20 polymorphic common OsHV-1 SNPs in the eight samples richest in viral reads (indicated by IDs).

further studies are necessary to assess the presence of herpeslike viruses in crustaceans (Bang, 1971; Ryazanova et al., 2015). Intriguingly, we reported Herpesvirales-like sequence elements in genomic scaffolds of C. teleta and Branciostoma spp. In agreement with Savin and colleagues (Savin et al., 2010) demonstrated that B. floridae sequence is highly similar to Abalone Malacoherpesviridae), we have shown that $C$. teleta-encoded DNA polymerase is more similar to bivalve Malacoherpesviridae, whereas both Branchiostoma-derived DNA polymerase clustered as an Malacoherpesviridae outgroup. Taken together, these findings suggest a broader presence of invertebrate-infecting Herpesvirales, representing former or extant (still undisclosed) viruses. Although the integration of genetic elements of large DNA viruses in invertebrate host genomes has already been reported (Drezen et al., 2017), further experimental validation is needed to definitively prove the integration of these sequences in host genomes.

The few predictable protein domains of Malacoherpesviridae (most of the Malacoherpesviridae genes are unique) suggested complex evolutionary paths, including gene transfer events from other dsDNA viruses (in particular, invertebrate viruses), bacteria, and also from mollusk hosts. Among other protein 
domains, we focused on BIR-containing proteins (putative inhibitors of apoptosis), because apoptotic responses are reported as one of the main bivalve countermeasures to infections due to the $\mu$ Var variant (Segarra et al., 2014b; He et al., 2015; Martenot et al., 2017) and BIR was found in several dsDNA and ssRNA viruses of invertebrates. Phylogenetic analysis of metazoan and viral BIRs did not indicate any robust evolutionary relationships, thus supporting the hypothesis of extensive gene transfer. We highlighted other common features of invertebrate dsDNA viruses by analyzing promoter sequence motifs involved in virus-protective DNA repair. Invertebrate dsDNA viruses analyzed in this work mainly encode one of the six searched HR promoter motifs, namely a truncated version of the chielement, whereas almost only Malacoherpesviridae are enriched in a classical meiotic recombination motif. These results support the interaction of Malacoherpesviridae with host recombination machinery, although probably with promoter motifs that are partially different from the vertebrate ones (and unknown). Commonalities emerged between Malacoherpesviridae and Whispovirus (White spot syndrome virus 1), namely shared domains and similar HR promoter enrichment patterns. An overlap between arthropod (in this case crustaceans) and bivalve viromes was recently reported for several RNA viral families (Shi et al., 2016) which might be a fascinating matter for future studies. Moreover, the reduced species-specificity for Malacoherpesviridae somewhat recalls the lack of virus-host codivergence observed in invertebrate RNA viruses (Shi et al., 2016), and calls for a broad, not species-specific mechanism of action.

Given the lack of permissive cell cultures, we used oyster RNA-seq samples as an effective (and unique) source of viral reads. In the so-called "RNA-seq dark matter" (Ponting and Belgard, 2010), the accidental or deliberate sequencing of OsHV1 -infected oysters can make millions of viral reads available, revealing active viral transcription. Despite the analysis of numerous Haliotid RNA-seq samples, no similar results could be achieved for abalones. Read mapping on Malacoherpesviridae unique genome regions as well as SNP analysis suggested the presence of more than one viral variant within and between RNA-seq samples. One virus type was preferentially present (i.e., more transcriptional active) in each host transcriptome sample, although a single virus encoding all the variants typical of different mollusk viruses might exist. Advanced ultra-deep RNA and DNA sequencing would be optimal to ascertain this point.

Although OsHV-1 was apparently suppressed in many of the analyzed samples (e.g., samples with less than a thousand viral reads), only proper controls could validate this hypothesis and assign the expressed viral ORFs to the persistent virus phase. Therefore, we only observed the broad expression of ORF76 in almost all samples with few viral reads. Interestingly, a limited structural similarity of ORF76 with the human nucleoporin (data not shown) postulates a role of this protein in the viral entry inside cell nucleus. Viral expression profiles were particularly informative in highly infected samples (supposed lithic virus phase), with most viral ORFs actively expressed and no predominant expression of single ORFs. Actually, the concordance between ORF expression ratios in these samples was a remarkable finding possibly revealing the functional importance of many viral proteins during virus replication, like in the case of the highly expressed dUTPase (ORF27, completely lacking nsSNPs) in agreement with (Segarra et al., 2014a,b). Functional validation based on in-situ hybridization, western blot and recombinant proteins is definitively needed to investigate the functional role of viral ORFs, as previously initiated (Martenot et al., 2016, 2017; Segarra et al., 2016).

Despite the lack of functional data for Malacoherpesviridae, conserved intergenic features might reveal hidden traits of virushost co-existence mechanisms. The current expansion of mollusk genomics is expected to answer some of the open questions mentioned in this work. Our analyses demonstrated that viral transcriptomics may greatly contribute to the understanding of the molecular facets of new viral variants including ORFs and aminoacidic changes crucially related to the pathogenic nature of certain variants, and may be useful to improve diagnostic qPCR-based methods.

\section{AUTHOR CONTRIBUTIONS}

UR and PV designed the analytical pipeline, UR performed the bioinformatic analysis, UR and PV prepared the manuscript.

\section{ACKNOWLEDGMENTS}

This research project was supported by the EU funded project VIVALDI (H2020 programme, $\left.\mathrm{n}^{\circ} 678589\right)$.

\section{SUPPLEMENTARY MATERIAL}

The Supplementary Material for this article can be found online at: http://journal.frontiersin.org/article/10.3389/fmicb. 2017.01515/full\#supplementary-material

Supplementary File 1 | Sequencing samples considered in the present work. Experiment description, SRA ID and sample description, number of millions reads, and number of identified Malacoherpesviridae reads are reported. Underlined samples with more than 1,000 viral reads are indicated as "high" samples.

Supplementary File 2 | Whole genome alignment of five Malacoherpesviridae genomes using progressive MAUVE. From top to bottom: OsHV-1, OsHV-1-SB, AVNV, AbHV-1-AUS, and AbHV-1-TAl. Conserved sequence blocks are reported in the same color whereas the available annotations are reported as empty boxes just below the colored blocks for each genome.

Supplementary File 3 | PFAM domains encoded by Herpesvirales. Domain name, PFAM accession, domain description, and length are reported. Each domain is labeled ("yes") if present in bivalve Malacoherpesviridae, gastropod Malacoherpesviridae, or other Herpesvirales. Malacoherpesviridae-exclusive domains are highlighted in yellow.

Supplementary File 4 | Distribution of six HR promoters in 2,665 dsDNA viral genomes. From left to right: virus name, NCBI accession, genome length, number of predicted proteins, and main host and, for the six recombination-initiating motifs, the table illustrates their quantity, their genome-length normalized frequencies, and their enrichment ratios.

Supplementary File $\mathbf{5}$ | Interactive visualization of the expression patterns of viral ORFs in C. gigas RNA-seq samples. Number of mapped reads per sample, non-normalized, and TPM expression values as well as total and non-synonymous SNPs are reported for any selected ORF. 
Supplementary File 6 | ORF expression analysis. Figure SF6_1. Correlation plot of Principal Component Analysis (PCA). Red and green dots indicate RNA-seq samples labeled as "high" or not labelled, respectively. Figure SF6_2. Clustering of viral ORFs. ORFs are clustered based on their TPM values using an Euclidean distance algorithm. "High" samples are framed in black. See the color legend at the bottom of the figure.

\section{REFERENCES}

Ahlers, L. R. H., Bastos, R. G., Hiroyasu, A., and Goodman, A. G. (2016). Invertebrate iridescent virus 6, a DNA virus, stimulates a mammalian innate immune response through RIG-I-Like receptors. PLoS ONE 11:e0166088. doi: 10.1371/journal.pone.0166088

Arias, C., Weisburd, B., Stern-Ginossar, N., Mercier, A., Madrid, A. S., Bellare, P., et al. (2014). KSHV 2.0: a comprehensive annotation of the Kaposi's sarcoma-associated herpesvirus genome using next-generation sequencing reveals novel genomic and functional features. PLoS Pathog. 10:e1003847. doi: 10.1371/journal.ppat.1003847

Arzul, I., Corbeil, S., Morga, B., and Renault, T. (2017). Viruses infecting marine molluscs. J. Invertebr. Pathol. 147, 118-135. doi: 10.1016/j.jip.2017.01.009

Bai, C., Wang, C., Xia, J., Sun, H., Zhang, S., and Huang, J. (2015). Emerging and endemic types of Ostreid herpesvirus 1 were detected in bivalves in China. J. Invertebr. Pathol. 124, 98-106. doi: 10.1016/j.jip.2014.11.007

Bailey, T. L., and Elkan, C. (1994). Fitting a mixture model by expectation maximization to discover motifs in biopolymers. Proc. Int. Conf. Intell. Syst. Mol. Biol. 2, 28-36.

Bang, F. B. (1971). Transmissible disease, probably viral in origin, affecting the amebocytes of the European shore crab, Carcinus maenas. Infect. Immun. 3, 617-623.

Brown, J. C. (2014). The role of DNA repair in herpesvirus pathogenesis. Genomics 104, 287-294. doi: 10.1016/j.ygeno.2014.08.005

Brown, J. C. (2017). Herpes simplex virus latency: the DNA repair-centered pathway. Adv. Virol. 2017:7028194. doi: 10.1155/2017/7028194

Brum, J. R., Ignacio-Espinoza, J. C., Roux, S., Doulcier, G., Acinas, S. G., Alberti, A., et al. (2015). Ocean plankton. Patterns and ecological drivers of ocean viral communities. Science 348:1261498. doi: 10.1126/science. 1261498

Burge, C. A., Strenge, R. E., and Friedman, C. S. (2011). Detection of the oyster herpesvirus in commercial bivalve in northern California, USA: conventional and quantitative PCR. Dis. Aquat. Org. 94, 107-116. doi: 10.3354/dao02314

Burioli, E. A. V., Prearo, M., Riina, M. V., Bona, M. C., Fioravanti, M. L., Arcangeli, G., et al. (2016). Ostreid herpesvirus type 1 genomic diversity in wild populations of Pacific oyster Crassostrea gigas from Italian coasts. J. Invertebr. Pathol. 137, 71-83. doi: 10.1016/j.jip.2016.05.004

Camacho, C., Coulouris, G., Avagyan, V., Ma, N., Papadopoulos, J., Bealer, K., et al. (2009). BLAST+: architecture and applications. BMC Bioinformatics 10:421. doi: 10.1186/1471-2105-10-421

Chang, P. H., Kuo, S. T., Lai, S. H., Yang, H. S., Ting, Y. Y., Hsu, C. L., et al. (2005). Herpes-like virus infection causing mortality of cultured abalone Haliotis diversicolor supertexta in Taiwan. Dis. Aquat. Org. 65, 23-27. doi: 10.3354/dao065023

Chuzhanova, N., Chen, J.-M., Bacolla, A., Patrinos, G. P., Férec, C., Wells, R. D., et al. (2009). Gene conversion causing human inherited disease: evidence for involvement of non-B-DNA-forming sequences and recombinationpromoting motifs in DNA breakage and repair. Hum. Mutat. 30, 1189-1198. doi: 10.1002/humu.21020

Corbeil, S., Williams, L. M., McColl, K. A., and Crane, M. S. J. (2016). Australian abalone (Haliotis laevigata, H. rubra and H. conicopora) are susceptible to infection by multiple abalone herpesvirus genotypes. Dis. Aquat. Organ. 119, 101-106. doi: 10.3354/dao02989

Corporeau, C., Tamayo, D., Pernet, F., Quéré, C., and Madec, S. (2014). Proteomic signatures of the oyster metabolic response to herpesvirus OsHV-1 $\mu$ Var infection. J. Proteomics 109, 176-187. doi: 10.1016/j.jprot.2014.06.030

Correa, A. M. S., Ainsworth, T. D., Rosales, S. M., Thurber, A. R., Butler, C. R., and Vega Thurber, R. L. (2016). Viral outbreak in corals associated with an in situ bleaching event: atypical herpes-like viruses and a new megavirus infecting symbiodinium. Front. Microbiol. 7:127. doi: 10.3389/fmicb.2016.00127

Darling, A. E., Mau, B., and Perna, N. T. (2010). progressiveMauve: multiple genome alignment with gene gain, loss and rearrangement. PLoS ONE 5:e11147. doi: 10.1371/journal.pone.0011147

Davison, A. J., Eberle, R., Ehlers, B., Hayward, G. S., McGeoch, D. J., Minson, A. C., et al. (2009). The order Herpesvirales. Arch. Virol. 154, 171-177. doi: 10.1007/s00705-008-0278-4

Davison, A. J., Trus, B. L., Cheng, N., Steven, A. C., Watson, M. S., Cunningham, C., et al. (2005). A novel class of herpesvirus with bivalve hosts. J. Gen. Virol. 86, 41-53. doi: 10.1099/vir.0.80382-0

Drezen, J.-M., Gauthier, J., Josse, T., Bézier, A., Herniou, E., and Huguet, E. (2017). Foreign DNA acquisition by invertebrate genomes. J. Invertebr. Pathol. 147, 157-168. doi: 10.1016/j.jip.2016.09.004

Edgar, R. C. (2004). MUSCLE: a multiple sequence alignment method with reduced time and space complexity. BMC Bioinformatics 5:113. doi: 10.1186/1471-2105-5-113

Gallo, A., Lampe, M., Günther, T., and Brune, W. (2017). The Viral Bcl-2 homologs of Kaposi's sarcoma-associated herpesvirus and rhesus rhadinovirus share an essential role for viral replication. J. Virol. 91:e01875-16. doi: 10.1128/JVI.01875-16

Green, T. J., Raftos, D., Speck, P., and Montagnani, C. (2015b). Antiviral immunity in marine molluscs. J. Gen. Virol. 96, 2471-2482. doi: 10.1099/jgv.0.0 00244

Green, T. J., Rolland, J.-L., Vergnes, A., Raftos, D., and Montagnani, C. (2015a). OsHV-1 countermeasures to the Pacific oyster's anti-viral response. Fish Shellfish Immunol. 47, 435-443. doi: 10.1016/j.fsi.2015.09.025

Grundhoff, A., Sullivan, C. S., and Ganem, D. (2006). A combined computational and microarray-based approach identifies novel microRNAs encoded by human gamma-herpesviruses. RNA N. Y. $N$ 12, 733-750. doi: 10.1261/rna.2326106

He, Y., Jouaux, A., Ford, S. E., Lelong, C., Sourdaine, P., Mathieu, M., et al. (2015). Transcriptome analysis reveals strong and complex antiviral response in a mollusc. Fish Shellfish Immunol. 46, 131-144. doi: 10.1016/j.fsi.2015. 05.023

Iranzo, J., Krupovic, M., and Koonin, E. V. (2016). The Double-Stranded DNA virosphere as a modular hierarchical network of gene sharing. MBio 7:e0097816. doi: 10.1128/mBio.00978-16

Khater, S., and Mohanty, D. (2015). In silico identification of AMPylating enzymes and study of their divergent evolution. Sci. Rep. 5:10804. doi: 10.1038/srep 10804

Kozomara, A., and Griffiths-Jones, S. (2014). miRBase: annotating high confidence microRNAs using deep sequencing data. Nucleic Acids Res. 42, D68-D73. doi: 10.1093/nar/gkt1181

Martenot, C., Gervais, O., Chollet, B., Houssin, M., and Renault, T. (2017) Haemocytes collected from experimentally infected Pacific oysters, Crassostrea gigas: detection of ostreid herpesvirus 1 DNA, RNA, and proteins in relation with inhibition of apoptosis. PLOS ONE 12:e0177448. doi: 10.1371/journal.pone.0177448

Martenot, C., Segarra, A., Baillon, L., Faury, N., Houssin, M., and Renault, T. (2016). In situ localization and tissue distribution of ostreid herpesvirus 1 proteins in infected Pacific oyster, Crassostrea gigas. J. Invertebr. Pathol. 136, 124-135. doi: 10.1016/j.jip.2016.04.002

Martenot, C., Travaillé, E., Lethuillier, O., Lelong, C., and Houssin, M. (2013). Genome exploration of six variants of the Ostreid Herpesvirus 1 and characterization of large deletion in OsHV-1 $\mu$ Var specimens. Virus Res. 178, 462-470. doi: 10.1016/j.virusres.2013.08.006

Moreau, P., Moreau, K., Segarra, A., Tourbiez, D., Travers, M.-A., Rubinsztein, D. C., et al. (2015). Autophagy plays an important role in protecting Pacific oysters from OsHV-1 and Vibrio aestuarianus infections. Autophagy 11, 516-526. doi: 10.1080/15548627.2015.1017188

Myers, S., Bottolo, L., Freeman, C., McVean, G., and Donnelly, P. (2005). A finescale map of recombination rates and hotspots across the human genome. Science 310, 321-324. doi: 10.1126/science.1117196

Oláh, P., Tombácz, D., Póka, N., Csabai, Z., Prazsák, I., and BoldogkÅŚi, Z. (2015). Characterization of pseudorabies virus transcriptome by Illumina sequencing. BMC Microbiol. 15:130. doi: 10.1186/s12866-0150470-0 
Pernet, F., Lupo, C., Bacher, C., and Whittington, R. J. (2016). Infectious diseases in oyster aquaculture require a new integrated approach. Philos. Trans. R. Soc. Lond. B. Biol. Sci. 371:20150213. doi: 10.1098/rstb.2015.0213

Petersen, T. N., Brunak, S., von Heijne, G., and Nielsen, H. (2011). SignalP 4.0: discriminating signal peptides from transmembrane regions. Nat. Methods 8, 785-786. doi: 10.1038/nmeth.1701

Piekna-Przybylska, D., Sharma, G., Maggirwar, S. B., and Bambara, R. A. (2017). Deficiency in DNA damage response, a new characteristic of cells infected with latent HIV-1. Cell Cycle 16, 968-978. doi: 10.1080/15384101.2017.1312225

Ponting, C. P., and Belgard, T. G. (2010). Transcribed dark matter: meaning or myth? Hum. Mol. Genet. 19, R162-R168. doi: 10.1093/hmg/ddq362

Ren, W., Chen, H., Renault, T., Cai, Y., Bai, C., Wang, C., et al. (2013), Complete genome sequence of acute viral necrosis virus associated with massive mortality outbreaks in the Chinese scallop, Chlamys farreri. Virol. J. 10:110. doi: 10.1186/1743-422X-10-110

Renault, T., Faury, N., Barbosa-Solomieu, V., and Moreau, K. (2011). Suppression substractive hybridisation ( $\mathrm{SSH}$ ) and real time PCR reveal differential gene expression in the Pacific cupped oyster, Crassostrea gigas, challenged with Ostreid herpesvirus 1. Dev. Comp. Immunol. 35, 725-735. doi: 10.1016/j.dci.2011.02.004

Renault, T., Moreau, P., Faury, N., Pepin, J.-F., Segarra, A., and Webb, S. (2012). Analysis of clinical ostreid herpesvirus 1 (Malacoherpesviridae) specimens by sequencing amplified fragments from three virus genome areas. J. Virol. 86, 5942-5947. doi: 10.1128/JVI.06534-11

Rosani, U., and Gerdol, M. (2016). A bioinformatics approach reveals seven nearly-complete RNA-virus genomes in bivalve RNA-seq data. Virus Res. doi: 10.1016/j.virusres.2016.10.009. [Epub ahead of print].

Rosani, U., Varotto, L., Domeneghetti, S., Arcangeli, G., Pallavicini, A., and Venier, P. (2015). Dual analysis of host and pathogen transcriptomes in ostreid herpesvirus 1-positive Crassostrea gigas. Environ. Microbiol. 17, 4200-4212. doi: 10.1111/1462-2920.12706

Roy, C. R., and Cherfils, J. (2015). Structure and function of Fic proteins. Nat. Rev. Microbiol. 13, 631-640. doi: 10.1038/nrmicro3520

Ryazanova, T. V., Eliseikina, M. G., Kalabekov, I. M., and Odintsova, N. A. (2015). A herpes-like virus in king crabs: characterization and transmission under laboratory conditions. J. Invertebr. Pathol. 127, 21-31. doi: 10.1016/j.jip.2015.02.003

Savin, K. W., Cocks, B. G., Wong, F., Sawbridge, T., Cogan, N., Savage, D., et al. (2010). A neurotropic herpesvirus infecting the gastropod, abalone, shares ancestry with oyster herpesvirus and a herpesvirus associated with the amphioxus genome. Virol. J. 7:308. doi: 10.1186/1743-422X-7-308

Segarra, A., Baillon, L., Faury, N., Tourbiez, D., and Renault, T. (2016). Detection and distribution of ostreid herpesvirus 1 in experimentally infected Pacific oyster spat. J. Invertebr. Pathol. 133, 59-65. doi: 10.1016/j.jip.2015.11.013

Segarra, A., Baillon, L., Tourbiez, D., Benabdelmouna, A., Faury, N., Bourgougnon, N., et al. (2014a). Ostreid herpesvirus type 1 replication and host response in adult Pacific oysters, Crassostrea gigas. Vet. Res. 45:103. doi: 10.1186/s13567-014-0103-x

Segarra, A., Mauduit, F., Faury, N., Trancart, S., Dégremont, L., Tourbiez, D., et al. (2014b). Dual transcriptomics of virus-host interactions: comparing two Pacific oyster families presenting contrasted susceptibility to ostreid herpesvirus 1 . BMC Genomics 15:580. doi: 10.1186/1471-2164-15-580

Segarra, A., Pépin, J. F., Arzul, I., Morga, B., Faury, N., and Renault, T. (2010). Detection and description of a particular Ostreid herpesvirus 1 genotype associated with massive mortality outbreaks of Pacific oysters, Crassostrea gigas, in France in 2008. Virus Res. 153, 92-99. doi: 10.1016/j.virusres.2010.07.011
Shi, M., Lin, X.-D., Tian, J.-H., Chen, L.-J., Chen, X., Li, C.-X., et al. (2016). Redefining the invertebrate RNA virosphere. Nature 540, 539-543. doi: $10.1038 /$ nature20167

Stern-Ginossar, N., Weisburd, B., Michalski, A., Le, V. T. K., Hein, M. Y., Huang, S.-X., et al. (2012). Decoding human cytomegalovirus. Science 338, 1088-1093. doi: 10.1126/science.1227919

Strahan, R., Uppal, T., and Verma, S. C. (2016). Next-Generation sequencing in the understanding of Kaposi's sarcoma-associated Herpesvirus (KSHV) biology. Viruses 8:92. doi: 10.3390/v8040092

Suttle, C. A. (2007). Marine viruses - major players in the global ecosystem. Nat. Rev. Microbiol. 5, 801-812. doi: 10.1038/nrmicro1750

Tan, T. L. S., Paul-Pont, I., Evans, O. M., Watterson, D., Young, P., Whittington, R., et al. (2015). Resistance of Black-lip learl oyster, Pinctada margaritifera, to infection by Ostreid herpes virus $1 \mu$ var under experimental challenge may be mediated by humoral antiviral activity. Fish Shellfish Immunol. 44, 232-240. doi: 10.1016/j.fsi.2015.02.026

Taylor, K. E., Chew, M. V., Ashkar, A. A., and Mossman, K. L. (2014). Novel roles of cytoplasmic ICP0: proteasome-independent functions of the RING finger are required to block interferon-stimulated gene production but not to promote viral replication. J. Virol. 88, 8091-8101. doi: 10.1128/JVI.00944-14

Tombácz, D., Csabai, Z., Oláh, P., Balázs, Z., Likó, I., Zsigmond, L., et al. (2016). Full-length isoform sequencing reveals novel transcripts and substantial transcriptional overlaps in a Herpesvirus. PLOS ONE 11:e0162868. doi: 10.1371/journal.pone.0162868

Wagner, G. P., Kin, K., and Lynch, V. J. (2013). A model based criterion for gene expression calls using RNA-seq data. Theory Biosci. Theor. Den Biowissenschaften 132, 159-164. doi: 10.1007/s12064-013-0178-3

Wang, H.-W., Sharp, T. V., Koumi, A., Koentges, G., and Boshoff, C. (2002). Characterization of an anti-apoptotic glycoprotein encoded by Kaposi's sarcoma-associated herpesvirus which resembles a spliced variant of human survivin. EMBO J. 21, 2602-2615. doi: 10.1093/emboj/21.11.2602

Wu, Y., Wei, B., Liu, H., Li, T., and Rayner, S. (2011). MiRPara: a SVM-based software tool for prediction of most probable microRNA coding regions in genome scale sequences. BMC Bioinformatics 12:107. doi: 10.1186/1471-2105-12-107

Xia, J., Bai, C., Wang, C., Song, X., and Huang, J. (2015). Complete genome sequence of Ostreid herpesvirus-1 associated with mortalities of Scapharca broughtonii broodstocks. Virol. J. 12, 110. doi: 10.1186/s12985-0150334-0

Xu, F., Wang, X., Feng, Y., Huang, W., Wang, W., Li, L., et al. (2014). Identification of conserved and novel microRNAs in the Pacific oyster Crassostrea gigas by deep sequencing. PLoS ONE 9:e104371. doi: 10.1371/journal.pone.0104371

Zhang, G., Fang, X., Guo, X., Li, L., Luo, R., Xu, F., et al. (2012). The oyster genome reveals stress adaptation and complexity of shell formation. Nature 490, 49-54. doi: $10.1038 /$ nature 11413

Conflict of Interest Statement: The authors declare that the research was conducted in the absence of any commercial or financial relationships that could be construed as a potential conflict of interest.

Copyright (c) 2017 Rosani and Venier. This is an open-access article distributed under the terms of the Creative Commons Attribution License (CC BY). The use, distribution or reproduction in other forums is permitted, provided the original author(s) or licensor are credited and that the original publication in this journal is cited, in accordance with accepted academic practice. No use, distribution or reproduction is permitted which does not comply with these terms. 